\title{
A universidade e a formação dos profissionais do próximo milênio: dificuldades e perspectivas ${ }^{1}$
}

\author{
Cleide Aparecida Faria Rodrigues ${ }^{2}$
}

Inicialmente quero agradecer o gentil convite que me foi formulado pelo Colegiado do Curso de Pedagogia para proferir esta palestra. Confesso que fiquei muito feliz com a oportunidade que estou tendo de dirigir-me aos alunos e professores deste curso que tanto respeito e admiro, pois no Curso de Pedagogia sempre identifiquei o fermento da renovação, o desejo de crescer e de aperfeiçoar-se e a preocupação não apenas com a aquisição dos conhecimentos e habilidades necessários ao exercício profissional, mas com a formação do homem e do cidadão.

Por outro lado, preocupou-me bastante a responsabilidade assumida, uma vez que acredito estarmos inciando hoje um novo ciclo na história do Curso e coube a mim a difícil tarefa de buscar as palavras adequadas a este momento tão significativo.

Assim sendo, convido-os a cons- truirmos juntos uma reflexão, mesmo que incompleta e provisória, que nos conduza a compreender um pouco mais a conjuntura atual e seus reflexos nas atividades universitárias e na formação de vocês, acadêmicos de Pedagogia, que serão os profissionais da educação do próximo milênio.

Há alguns dias, lendo uma publicação da Universidade Federal do Rio Grande do Sul, encontrei um texto do professor Ronai Pires da Rocha que despertou a minha atenção pela beleza e propriedade com que o autor representou uma realidade que nos angustia profundamente: aquilo que ele denominou dormência institucional. E é com uma pequena parte deste artigo que pretendo iniciar a nossa reflexão.

Assim escreve o professor PIRES DA ROCHA:

Pessoas e instituições, ao modo de

\footnotetext{
${ }^{1}$ Aula inaugural do Curso de Pedagogia. Universidade Estadual de Ponta Grossa, mar. 1999.

${ }^{2}$ Pró-Reitora de Graduação da UEPG.

Olhar de professor, Ponta Grossa, 2 (2):53-60, nov. 1999.
} 
plantas, por vezes desenvolvem mecanismos de proteção em relação a estímulos e desafios do ambiente. Em algumas circunstâncias, esses mecanismos entram em processo de dormência sem quebra, o que provoca estados de torpor e mesmice institucional. Pensem nessa imagem: uma planta adormecida está viva e trabalhando, mesmo quando cumpre a rotina da hibernação. Se ela tiver o número adequado de horas de frio, um belo dia a dormência é rompida. Caso contrário, a floração até mesmo virá, mas a safra não será a mesma. Grande parte das universidades parecem viver uma vida embalada em ritmo de dormência. Energias circulam, forças se espreguiçam, mas delas não brotam floradas contínuas e vigorosas. Aqui ou ali surgem tímidos ramos, mas é como se fossem contidas por um clima inadequado (1996, p.71).

Afirma, ainda, o referido professor que também no interior dos cursos essa dormência muitas vezes se instala. O curso chega, se institui e nunca mais sai do lugar, pois o que o caracteriza é a imobilidade. Não mudam os currículos, não evoluem os programas, não se experimentam novas metodologias, não se ousa enveredar por novos caminhos de pesquisa. Cada professor, como um rei, é intocável em sua disciplina. Às vezes sopram ventos de mudança, por ini- ciativa ou atrevimento de um professor ou de alguns alunos mais ousados, mas tudo acaba voltando ao mesmo lugar.

Como, então, induzir a quebra da dormência, como disparar o dispositivo hormono-institucional capaz de fazer vibrar novas floradas acadêmicas? É possivel mudar esse estado de coisas? (ROCHA, 1996, p.71).

Esse texto, sem dúvida, nos faz pensar: estará a nossa universidade ou o nosso curso em estado de dormência? E, se está, o que fazer para rompê-la?

Infelizmente, em certos casos, creio que a resposta é sim; a acomodação, o conformismo, a passividade não estão distantes dos nossos muros, nem dos muros de outras Instituições de Ensino Superior.

Todavia este não parece ser o caso do nosso Curso de Pedagogia que, mesmo sabendo-se no meio do furacão da crise financeira que varre o país e fragiliza as instituições, quer inovar.

Provavelmente, mentalidades mais conservadoras dirão que o momento é impróprio e o risco muito grande. Pergunto, então: - qual seria o momento certo? Será que não é na crise que precisamos ser criativos e ousar? Será que existe mau momento para se obter belas floradas acadêmicas? Certamente não. Ao contrário, em períodos de crise é que se faz necessário que soprem os ventos da mu- 
dança e eu me orgulho de saber que este curso tem coragem suficiente para tentar alçar novos vôos, iniciando o ano de 1999 com uma proposta renovada de trabalho, fruto de estudos e discussões de seus professores e alunos.

Todavia, em momentos como este também é preciso cautela. Concordo com Gramsci quando afirma que para procedermos a mudanças precisamos de "otimismo da vontade e pessimismo da inteligência". O otimismo da vontade será a mola propulsora que nos levará sempre adiante, que nos fará persistir, sem nunca esmorecer. Por outro lado, não podemos entregar-nos a um otimismo ingênuo, que não percebe os condicionantes sóciohistóricos que podem levar-nos ao fracasso, daí a importância do pessimismo da inteligência, capaz de apontar desafios e barreiras a serem enfrentados e vencidos.

Assim sendo, caros colegas e acadêmicos, precisamos de muito otimismo, de muita confiança em nossos propósitos para levar adiante este projeto, mas precisamos também do pessimismo saudável que nos aponte as dificuldades, os esforços e sacrifícios que serão necessários para que possamos atingir nossas metas. E, mais ainda, precisamos definir, com muita clareza, onde queremos chegar, para que saibamos "escolher o caminho e o jeito de caminhar" (como diria o poeta Thiago de Mello).

Não basta aspirar a floradas vigorosas, precisamos criar as condições para que elas aconteçam e conhecer bem o terreno onde estamos fazendo nossa plantação. E que terreno é esse?

Esta questão nos remete ao contexto nacional e mundial, aos possíveis limites que ele vem impondo às universidades e às novas exigências que nos são colocadas em termos de formação profissional.

Analisando o atual momento histórico, podemos antever algumas tendências mundiais que se refletem na educação. Dentre elas destacamos a globalização, as políticas neoliberais e os incríveis avanços da ciência e da tecnologia.

A globalização é, hoje, o conceito-chave para compreendermos a realidade em que estamos vivendo. Ela consiste, segundo GIDDENS, em um processo de alongamento do tempoespaço (apud DIAS SOBRINHO, 1997, p.15), ou seja, as conexões entre pessoas, grupos e instituições ocorrem, hoje, se enredando por toda a superfície da terra. Ela não se expressa apenas pela mundialização da economia e pela queda das fronteiras nacionais quando se trata de expandir capitais e serviços ou de deslocar rapidamente fortunas de um para o outro lado do globo. Ela significa também a globalização do poder e da informação (CARVALHO,1997).

Observa-se hoje o enfraquecimento do Estado/Nação, paralelo ao fenômeno de concentração do poder nas mãos dos grandes órgãos financiadores internacionais, como o Fundo Monetário Internacional (FMI) e o 
Banco Mundial (BIRD), que ditam as políticas a serem seguidas pelos diversos países do mundo.

No campo da informática e das telecomunicações, as grandes redes de comunicação global, cujo exemplo mais conhecido é a Internet, transformaram o mundo numa vasta aldeia em que a informação chega instantaneamente a qualquer lugar do planeta, favorecendo o acesso ao conhecimento a um número cada vez maior de pessoas.

Por outro lado, aumenta, cada vez mais, a distância entre os instruídos e os não escolarizados, sendo que estes últimos estão cada vez mais marginalizados, num mundo onde a principal moeda não é mais o dinheiro, mas sim o conhecimento, e onde a aceleração das mudanças transforma rapidamente os conhecimentos adquiridos em noções ultrapassadas.

Outra noção fundamental para compreendermos o que se passa ao nosso redor refere-se às políticas neoliberais, hegemônicas no atual momento histórico. O neoliberalismo, versão contemporânea da doutrina liberal que favorece a reorganização do capitalismo nos moldes oligopolista e transnacional, vem sendo imposto pelas nações mais ricas e pelos organismos financiadores do dinheiro internacional aos países pobres, que nem sequer chegaram aos patamares mínimos de bem-estar social. Suas propostas pretendem ser a única solução para a saída da crise financeira que assola o planeta, implicando na drástica redução do tamanho do Estado, na ampla privatização dos serviços públicos, no enfraquecimento do poder dos sindicatos, num rígido controle do dinheiro e em cortes nos benefícios sociais, sendo que os setores mais prejudicados são justamente aqueles que garantem um certo bemestar às populações de baixa renda, como habitação, saúde e educação (RODRIGUES, 1997).

A conjugação desses dois fatores com o incrível progresso científico e tecnológico dos últimos anos tem colocado diante de nós, administradores, professores e alunos de uma universidade pública, imensos desafios a serem superados. Dentre esses inúmeros desafios, quero destacar aqueles que, segundo tenho constatado, vêm afetando diretamente a formação dos profissionais e a qualidade do ensino universitário. São eles: a aceleração da história, a elevação dos custos dos sistemas universitários, a dificuldade de manutenção da qualidade acadêmica, a relativização do valor do diploma e o individualismo que marca as relações sociais nas sociedades contemporâneas.

A velocidade das atuais transformações faz com que o homem contemporâneo experimente um sentimento de incapacidade em compreender o significado, a extensão e as conseqüências das inovações e de prever, com certa segurança, os cenários futuros. Os impactos, hoje, são simultâneos e globais - qualquer transformação em um setor localizado da vida humana inter- 
fere no conjunto universal da sociedade. "Fomos educados para um mundo que já não existe e estamos educando as novas gerações para um mundo que brevemente será outro" (DIAS SOBRINHO,1997, p.6). Uma grande parte dos conhecimentos que ensinamos já está ultrapassada no exato momento do ensino e nós sequer nos apercebemos disso. Profissões desaparecem rapidamente e surgem outras com a mesma rapidez.

- Como, então, preparar os profissionais do futuro?

Isso nos coloca diante do desafio de aprender a aprender. Muito mais do que nos preocuparmos em armazenar idéias prontas devemos nos preparar para buscar a informação de modo autônomo e para produzir novos conhecimentos, o que coloca em cheque todos os métodos tradicionais de ensino.

A rapidez das mudanças também exige atualização permanente dos profissionais, cuja educação não termina com a obtenção do diploma, mas, ao contrário, deve durar a vida inteira. Dos sistemas acadêmicos espera-se a agilidade suficiente para incorporar o novo, por meio de alterações curriculares, programáticas e metodológicas, pela introdução de novas tecnologias e equipamentos, pelo desenvolvimento de novas formas de tratar a pesquisa e a produção do conhecimento. Dos profissionais espera-se capacidade de trabalhar com conhecimentos interrelacionados $\mathrm{e}$ integrados, flexibilidade intelectual, capacidade de adaptar-se a situações novas, senso crítico, criatividade, raciocínio lógico, habilidade de trabalhar com diferentes códigos e linguagens, boa capacidade de comunicação e outras habilidades que só podem ser adquiridas na escola, o que explica, em parte, o crescente interesse de diversos setores sociais, inclusive do setor empresarial, pela qualidade da escola pública.

O diploma hoje, embora importante, não assegura o emprego; ele é, antes, a prova da formação recebida e o instrumento necessário para iniciar uma vida profissional que será marcada por inúmeras transformações e pela busca incessante de novos conhecimentos, de novas tecnologias, de novos recursos que permitam ao profissional manter-se atualizado no interior de uma cultura e de uma sociedade em constante mudança.

Despertar essa atitude de curiosidade intelectual, de busca constante do novo é, sob o meu ponto de vista, uma das tarefas mais importantes que a universidade deve desempenhar nos próximos anos e é também uma das tarefas que a universidade não tem desempenhado a contento, uma vez que os nossos alunos dedicam a maior porte do tempo disponível para o estudo, tentando assimilar idéias prontas, em detrimento de suas próprias idéias. Daí, a importância de mudanças na estrutura e na metodologia dos cursos de graduação, de modo a incentivar o raciocínio, a pesquisa e a produção pessoal dos acadêmicos e, 
por que não dizer, também dos professores.

Todavia, mudar uma situação já consolidada por anos de rotina e de descaso das autoridades para com a educação não é tão simples como pode parecer e não depende exclusivamente da boa vontade de professores e acadêmicos. Exige também recursos financeiros e materiais compatíveis com o atual estágio do desenvolvimento científico e tecnológico.

A aceleração da mudança torna os sistemas acadêmicos rapidamente obsoletos, obrigando as instituições a buscar novos e mais modernos instrumentos de trabalho, sob pena de estarem ministrando um ensino ultrapassado ou de não terem condições de competir no campo da pesquisa. Essa situação vem se agravando, sobretudo nas instituições públicas de ensino, que vêem seus equipamentos sucateados sem a possibilidade de substituí-los, em virtude da incapacidade do setor público de financiar os custos operacionais do sistema, situação que se torna ainda mais dramática a partir da implementação das políticas neoliberais, com seus cortes sobretudo nas áreas sociais.

Sabemos que as universidades precisam buscar, cada vez mais, a sua autonomia financeira, administrativa e didático-pedagógica, uma vez que pouco se pode esperar do Estado. Torna-se patente, nos dias atuais, que a excelência acadêmica vai depender muito mais dos esforços da comunidade universitária e daquilo que ela for capaz de produzir, do que dos recursos do tesouro público.

Essa excelência dependerá também de uma aproximação cada vez maior entre universidade e comunidade, do estabelecimento de parcerias entre os setores público e privado, e da capacidade da universidade, através dos esforços de seu corpo docente e discente, dar respostas cada vez mais eficazes ao anseios da comunidade em que está inserida.

Todas essas mudanças estão apontando para um novo perfil do profissional a ser formado pelas universidades, um profissional capaz de situar-se adequadamente no mundo do trabalho sem escravizar-se a ele, um profissional em que conhecimentos, competências diversas e valores éticos possam integrar-se para formar o homem e o cidadão, alguém capaz de ultrapassar o individualismo reinante na atual sociedade, atuando em favor da coletividade.

Aproximar-se da comunidade externa e fortalecer os laços existentes na comunidade interna, eis outro grande desafio que a universidade de hoje precisa enfrentar e vencer, opondo-se às premissas neoliberais que, com sua lógica do lucro, do consumismo, do dinheiro e da competitividade, vêm acentuando, cada vez mais, o individualismo em oposição à solidariedade e igualdade.

Segundo DIAS SOBRINHO (1997, p.10),

nesta que se convencionou chamar 
de terceira revolução industrial, o individualismo, a ameaça permanente e muito próxima da exclusão, o valor exacerbado dos bens materiais criam indivíduos submissos e desligados das lutas sociais.

É contra esses pseudovalores que a universidade precisa lutar, evitando que a sociedade seja indiferente ante a força avassaladora da técnica e frente ao individualismo exacerbado do sistema capitalista que não nos permite enxergar a diversidade e as diferenças, impondo a toda a humanidade uma referência uniforme e geral, que contribui para aumentar ainda mais a massa dos excluídos nos vários pontos do mundo.

Mais do que nunca a sociedade humana requer pessoas com mentes abertas e rigorosamente críticas, com o domínio das teorias integradoras e a compreensão dos movimentos de transformação nos níveis mundiais e intercul-turais [...]. A universidade deve estar atenta para a necessidade indescartável de produzir a cidadania, o sentido público da construção do social e da autonomia pessoal, os valores da cooperação e da solidariedade e socia-lidade (DIAS SOBRINHO, 1997, p.1436).

Esta é, segundo minha concepção, a grande tarefa do educador no momen- to presente, e estes são os desafios que o Curso de Pedagogia deverá enfrentar, se não quiser ser mais um a mudar para permanecer no mesmo lugar.

Espero sinceramente que, enquanto coletivo, tenhamos coragem, sabedoria e espírito de equipe para realizar aquilo que estamos nos propondo e espero também que nossas naturais diferenças ideológicas ou políticas não nos impeçam de trabalharmos juntos e de atingirmos os objetivos traçados para o Curso, pois, com isso, muito terão a ganhar os acadêmicos e a Universidade Estadual de Ponta Grossa.

Com estas palavras encerro a minha reflexão, desejando a todos um ano letivo de muito trabalho, bastante agitado, conturbado mesmo, mas fértil em realizações. Que possamos, finalmente, colher as vigorosas floradas acadêmicas que há tanto tempo vimos esperando.

Muito obrigada.

\section{REFERÊNCIAS BIBLIOGRÁFICAS}

1 CARVALHO, Carlos Alberto. A universidade do ano 2000. Informação. PUCRS, p.6-7, 1997.

2 DIAS SOBRINHO, José. Universidade e construção do futuro. Cadernos de apoio ao ensino. Maringá, UEL, p.5-36, dez., 1997. 
3 ROCHA, Ronai Pires da. Dormência, lingüiça e desesperanças de outono. In: MORAES, Vera Regina Pires (org.). Melhoria do ensino e capacitação docente. Porto Alegre: Ed. Universidade / UFRGS, 1996, p.71-77.

4 RODRIGUES, Cleide Aparecida Faria. Caminhos e descaminhos da política educacional paranaense: a articulação entre $1^{0}$ e $2^{\circ}$ graus de ensino e a educação continuada de docentes. Ponta Grossa, 1997. Dissertação de Mestrado. Universidade Estadual de Ponta Grossa. 